\title{
Polypyrrole-wrapped carbon nanotube composite films coated on diazonium-modified flexible ITO sheets for the electroanalysis of heavy metal ions
}

\author{
Momath Lo ${ }^{1,2,3, *}$, Mahamadou Seydou ${ }^{4}$, Asma Bensghaïer ${ }^{3}$, Remy Pires $^{3}$, \\ Diariatou Gningue-Sall ${ }^{1}$, Jean-Jacques Aaron ${ }^{2, *}$, \\ Zineb Mekhalif ${ }^{5}$, Joseph Delhalle ${ }^{5}$, Mohamed M. Chehimi ${ }^{3, *}$

\footnotetext{
${ }^{1}$ Université Cheikh Anta Diop, Faculté des Sciences, BP 5005, Dakar-Fann, Sénégal

${ }^{2}$ Université Paris-Est, Laboratoire Géomatériaux et Environnement, 5 Bd. Descartes, 77454 Marne-la-Vallée Cedex 2, France

${ }^{3}$ Univ Paris Est Creteil, CNRS, ICMPE, UMR7182, F-94320 Thiais, France

${ }^{4}$ Univ Paris Diderot, Sorbonne Paris Cité, ITODYS, UMR 7086 CNRS, 15 rue J-A de Baï, 75205 Paris Cedex 13, France

${ }^{5}$ Laboratory of Chemistry and Electrochemistry of Surfaces (CES), Universityof Namur, rue de Bruxelles, 61, B-5000 Namur, Belgium
}

Corresponding author (Mohamed M. Chehimi): chehimi@icmpe.cnrs.fr

\begin{abstract}
Highly sensitive multicomponent materials designed for the recognition of hazardous compounds request control over interfacial chemistry. The latter is key parameter in the construction of the sensing (macro)molecular architectures. In this work, multi-walled carbon nanotubes (in short, CNTs) were deposited on diazonium-modified flexible ITO electrodes prior to electropolymerization of pyrrole. This three step process, including diazonium electroreduction, deposition of CNTs and electropolymerization, provided adhesively bonded polypyrrole-wrapped CNT composite coatings on aminophenyl-modified flexible ITO sheets. The aminophenyl (AP) groups were attached to ITO by electroreduction of the in situ generated aminobenzenediazonium compound in aqueous, acidic medium. For the first time, polypyrrole (PPy) was electrodeposited in the presence of both benzenesulfonic acid (dopant) and ethylene glycol-bis(2-aminoethylether)-tetraacetic acid (EGTA) which acts as a chelator. The flexible electrodes were characterized by XPS, Raman and scanning electron microscopy (SEM) which provided strong supporting evidence for the wrapping of CNTs by the electrodeposited PPy. Indeed, the CNT average diameter increased from $18 \pm 2.6 \mathrm{~nm}$ to $27 \pm 4.8$, $35.6 \pm 5.9$ and $175 \pm 20.1$ after 1,5 and 10 of electropolymerization of pyrrole. The $\mathrm{PPy} / \mathrm{CNT} / \mathrm{NH}_{2}$-ITO films generated by this strategy exhibit significantly improved stability and higher conductivity compared to a similar PPy coating without any embedded CNTs as assessed by from electrochemical impedance spectroscopy measurements. The potentiometric response was linear in the $10^{-8}-3 \times 10^{-7} \mathrm{~mol} . \mathrm{L}^{-1} \mathrm{~Pb}$ (II) concentration range and the detection limit was $2.9 \times 10^{-9}$ mol. $\mathrm{L}^{-1}$ at $\mathrm{S} / \mathrm{N}=3$. The EGTA was found to drastically improve selectivity for $\mathrm{Pb}$ (II) over $\mathrm{Cu}$ (II). To account for this improvement, density functional theory (DFT) was employed to calculate the EGTA-metal ion interaction energy which was found to be -374.6 and $-116.4 \mathrm{~kJ} / \mathrm{mol}$ for $\mathrm{Pb}(\mathrm{II})$ and $\mathrm{Cu}(\mathrm{II})$, respectively, considering solvation effects.
\end{abstract}

This work demonstrates the power of a subtle combination of diazonium coupling agent, CNTs, chelators and conductive polymers to design high-performance electrochemical sensors for environmental applications.

Keywords : Polypyrrole; diazonium; multiwalled carbon nanotubes; chelator; heavy metal ions; electrochemical sensors. 


\section{Introduction}

Extensive research on carbon nanotubes (CNTs) in the fields of applied physics, chemistry, and materials science and engineering has progressed at a remarkable pace owing to the CNTs outstanding mechanical properties, good electronic conductivity, 1D structure, nanometer size diameter and high-accessible surface area [1]. In order to design ultra-sensitive sensors, CNTs have been used either as such or after modification by a variety of ways $[2,3,4,5]$.

Conductive polymers (CPs), including polypyrrole (PPy), polyaniline (PANI), and polythiophene (PT), constitute a class of materials which is widely investigated for their attractive applications in electronic devices [6], super-capacitors [7,8], thermoelectric power generators [9], and gas and ion sensors [10,11,12]. Particularly, PPy and its derivatives play a leading role due to the relative low oxidation potential of the corresponding monomers, high stability and excellent electrical properties in organic and aqueous solvents [13]. Owing to these features, polypyrroles are considered as ideal polymeric materials for building various sensors.

In a global effort to combine the best of two worlds, PPy/CNT composites were prepared via chemical [14,15], electrochemical [16], sonochemical [17] and radiation induced routes [18]. Indeed, strong interactions between the highly delocalized $\pi$-electrons of CNTs and $\pi$ electrons of the polymer skeleton favor the electron/hole transfer between CNTs and CPs $[19,20]$. It is worth to note that CNTs impart the polymer film electrical conductivity which results in fast electrode kinetics [21]. Taking advantage of the salient and complementary features of CNTs and PPy, various electrochemical sensing systems based on PPy/CNT nanocomposites have been proposed for biomedical and environmental applications $[22,23,24,25,26,27]$.

The main purpose of this work is to rationally modify flexible ITO electrodes with sensitive PPy films bearing embedded CNTs for the selective recognition of heavy metallic ions. We have previously demonstrated that excellent adhesion of PPy coating on flexible ITO required the use of coupling agents [28,29]. Otherwise, an immediate failure of the PPy coating occurred upon simple washing of the film with water. Sonication also induced a total delamination. Indeed, excellent adhesion was achieved on aminophenyl-modified ITO electrodes [28], as noted elsewhere for amino-modified materials [30]. For the preparation of composite films of PPy and CNTs, two options are proposed: either polymerization of pyrrole 
on ITO electrode in the presence of CNT dispersion, or direct polymerization of pyrrole on CNT-coated ITO. This second option has been selected as first trials indicated robust CNT adhesion to arylated ITO surfaces (cf. section 3).

Besides this interfacial aspect, in a previous paper, we reported on the doping of PPy with benzenesulfonic acid (BSA) and the remarkable electrochemical and electroanalytical properties of PPy [31]. Herein, we combine BSA with the strong ethylene glycol-bis(2aminoethylether)-tetraacetic acid (EGTA) chelator [32]. The latter is similar to EDTA, but possesses an ethylene glycol unit. Since our ongoing research work targets the removal of metal ions, we reasoned that EGTA chelator would add up two oxygen atoms with 2 electron pairs and thus enhance the complexation of heavy metal ions. EDTA-grafted polypyrrole was previously employed for the selective electrochemical detection of heavy metals ions [33], while pyrrole was electropolymerized in the presence of single walled CNTs and EDTA on stainless steel electrodes [34]. Herein, we conjugate the versatile surface chemistry of aryl diazonium salts on flexible ITO electrodes, CNTs, and electrosynthesized PPy co-doped with BSA and EGTA. This allowed us to construct, in a unique manner, novel $\mathrm{NH}_{2}$-ITO/CNT/PPy electrodes for the capture of heavy metal ions. These flexible electrodes are easy to handle and to cut to the desired size with scissors.

The flexible sensing electrodes and reference materials were characterized using Raman, XPS, SEM and electrochemical impedance spectroscopy. Electroanalytical performances of the sensors were determined by differential pulsed voltammetry (DPV).

\section{Experimental}

\subsection{Material and Reagents.}

CNTs of the type Nanocyl 7000, 2-9 nm diameter (carbon purity 99\%), were purchased from Sigma Aldrich. Sodium nitrite (Sigma-Aldrich, $\geq 99.0 \%$ ), anhydrous acetonitrile (99.8\%, noted ACN), chloric acid, ferrocene (Sigma-Aldrich) and potassium chloride were used without further purification. Pyrrole (Aldrich, purity $\geq 98 \%$ ), benzene sulfonic acid (BSA) and p-phenylenediamine were refrigerated prior to use. All aqueous solutions were prepared using Milli-Q ultrapure water (MQ $18.2 \mathrm{~cm}$ ). The flexible ITO-coated plastic sheets were purchased from Peccel (Japan). 


\subsection{In situ diazonium modification of ITO electrode}

We have generated in situ para-aminobenzenediazonium cation from 1,4-phenylenediamine precursor in order to derivatize ITO sheets with surface bound aminophenyl groups $\left(\mathrm{NH}_{2}-\right.$ ITO). The ITO-coated polyethylene naphthalene (ITO-PEN) surface was cleaned by sonication in a solution containing water and ethanol for $2 \mathrm{~min}$. After sonication, the electrode was washed with de-ionized water. The electrografting of diazonium salt generated in situ was performed using a three-electrode system, including a working electrode (ITO PEN, area $\sim 5 \mathrm{x} 5 \mathrm{~mm}$ ), and a stainless steel grid, used as counter electrode. All potentials were reported versus the saturated calomel electrode. The diazonium salt was produced by mixing $1 \mathrm{mM}$ of diazonium with $0.5 \mathrm{M} \mathrm{HCl}$ in glassy beaker during $30 \mathrm{~min}$ before adding $10 \mathrm{~mL}$ of $1 \mathrm{mM}$ aqueous solution of $\mathrm{NaNO}_{2}$. The resulting solution was stirred for $1 \mathrm{~h}$. The electrografting was then carried out either by cyclic voltammetry $(\mathrm{CV})$ at a scan rate of $50 \mathrm{mVs}^{-1}$ or under potentiostatic conditions (-0.8 V/SCE for $45 \mathrm{~s})$. We used the Biologic SP 150 potentiostat interfaced with the EC Lab software suite to conduct all electrochemical experiments. The blocking effect of the attached aminophenyl groups as well as the electrochemical activity of the bare and modified ITO electrodes were investigated by $\mathrm{CV}$ using $1 \mathrm{mM} \mathrm{Fe}(\mathrm{CN})^{3-/ 4-}$ redox probe. The CVs were recorded between -0.4 and $0.6 \mathrm{~V} / \mathrm{SCE}$ at a scan rate of $50 \mathrm{mV} / \mathrm{s}$.

\subsection{Purification and deposition of CNTs on diazonium-modified ITO}

The process of purification was adapted from [35]. Briefly, $50 \mathrm{mg}$ of crude CNTs was mixed with $20 \mathrm{ml}$ of $6 \mathrm{M} \mathrm{NaOH}$ solution in a round-bottomed flask and then heated under constant agitation at $170 \mathrm{C}$ for $1 \mathrm{~h}$. The mixture was cooled, filtered and washed with copious amounts of water until neutral $\mathrm{pH}$ and ultimately washed with acetone and dried in air.

In a second step, $25 \mathrm{mg}$ of CNTs were dispersed in $37 \% \mathrm{HCl}$ solution under reflux for 30 minutes [36]. The mixture was cooled, filtered and washed with water until neutral $\mathrm{pH}$ was obtained and ultimately washed with acetone and dried in air. This oxidation procedure in concentrated acid is well-known to provide carbon nanotubes with reactive carboxylic acid groups [37].

After activation, $1 \mathrm{mg}$ of purified CNTs was dispersed by ultrasonication in $10 \mathrm{~mL}$ ACN for 1h. The CNTs/ $\mathrm{NH}_{2}$-ITO electrode surface was obtained by adding $50 \mu \mathrm{L}$ of CNTs in ACN and evaporating the solvent after dropwise addition on $\mathrm{NH}_{2}$-ITO surface. We observed strong adherence of the sonicated CNTs on $\mathrm{NH}_{2}$-ITO surface. 


\subsection{Preparation of PPy films on ITO surface}

Prior to the electropolymerization, CNT-decorated ITO electrodes were sonicated in a solution containing water and ethanol for $2 \mathrm{~min}$. PPy was prepared by electropolymerization on bare ITO (Route 1), $\mathrm{NH}_{2}$-ITO (Route 2), $\mathrm{CNT} / \mathrm{NH}_{2}$-ITO (Route 3 ) in the -1 to $1.2 \mathrm{~V}$ potential range, in an aqueous solution ( $20 \mathrm{ml}$ total volume) containing $0.01 \mathrm{M}$ of BSA, 0.01 M EGTA, $0.03 \mathrm{M} \mathrm{NaOH}$ and $0.1 \mathrm{M}$ pyrrole.

\subsection{Spectroscopic and electrochemical characterization of PPy-modified electrodes}

Horiba Lab RAM HR Evolution was used to record Raman spectra at RT. The beam wavelength was $638 \mathrm{~nm}$.

XPS measurements were carried out using K Alpha apparatus (Thermo Fisher Scientific) fitted with monochromated Al X-ray source $(\mathrm{hv}=1486.6 \mathrm{eV}$; spot size $=400 \mu \mathrm{m})$. The pass energy was 80 and $200 \mathrm{eV}$ for the narrow and the survey spectral regions, respectively. A flood gun was used for static charge compensation.

Electrochemical measurements were carried out using a Biologic SP105 potentiostat and ECLab as a monitoring software. The blocking effect of the electrochemical activity of the modified ITO surface was investigated by $\mathrm{CV}$, using $\mathrm{Fe}(\mathrm{CN})^{3-/ 4-}$ redox couple and recorded between -0.4 and $1 \mathrm{~V}$ at a scan rate of $50 \mathrm{mV} / \mathrm{s}$. The electrochemical impedance spectra (EIS) were recorded in the frequency range from $100 \mathrm{mHz}-10 \mathrm{kHz}$. The equivalent electrical circuit was determined using EC-Lab software.

\subsection{Morphological characterization of PPy-modified electrodes}

The films were imaged using a Zeiss Merlin Field Emission Scanning Electron Microscope (FE-SEM). Prior to analysis, all samples were coated with a $2 \mathrm{~nm}$ thin layer of platinum/palladium alloy using a Cressington 208HR sputter-coater coupled with a cressington MTM-20 thickness controller. The CNT diameters were measured using an image analysis software (ImageJ, NIH). More than 100 measurements were performed for each sample in order to determine a CNT size distribution. Each measurement was marked with a white solid line. 


\section{Results and Discussion}

Before reporting the results and discussing them, it is worth to give some useful information on the interfacial aspects of the actual sensors. The pending question was: is it necessary to apply an adhesive layer on ITO for the attachment of CNTs, or do they stick efficiently to bare ITO? The first trials demonstrated that CNTs had poor adhesion to bare ITO, a behavior similar to that of PPy. To address this limitation and overcome the adhesion problems, flexible ITO electrodes were modified with aminophenyl groups by electroreduction of aminobenzenediazonium. We noted a better adhesion and resistance of CNTs to intensive washing with water and even to ultrasonication. This has motivated us to explore this route in view of building PPy/CNT composite coatings on flexible ITO in three steps: $(i)$ preparation of aminophenyl-modified flexible ITO ( $\mathrm{NH}_{2}$-ITO) [28], (ii) purification and ultrasonic dispersion of CNTs prior to deposition on $\mathrm{NH}_{2}$-ITO, (iii) electropolymerization of pyrrole in the presence of EGTA on CNT-coated $\mathrm{NH}_{2}$-ITO.

This strategy presents several advantages: CNTs were deposited on $\mathrm{NH}_{2}$-ITO by drop casting, which limits the loss of CNTs. Electropolymerization of pyrrole in a CNT suspension would have generated nanocomposites in suspension that would not have adhered to the surface by strong intermolecular interactions, therefore inducing detachment of the nanocomposite. Instead, coating CNTs on $\mathrm{NH}_{2}$-ITO is interesting because the aminophenyl groups serve as coupling agents for CNTs through $\mathrm{n}-\pi$ electronic interactions. Indeed, $\mathrm{sp}^{2}$ carbon nanomaterials are known to have excellent adhesion to diazonium-modified surfaces [38].

With improved adhesion of CNTs to ITO through an aryl coupling agent monolayer, we anticipated obtaining strongly attached PPy to both the immobilized CNTs and the underlying aryl-modified ITO.

\subsection{Preparation of PPy films on bare ITO, $\mathrm{NH}_{2}-\mathrm{ITO}$ and $\mathrm{CNT} / \mathrm{NH}_{2}-\mathrm{ITO}$ electrodes}

Scheme 1 illustrates the strategies for making adhesively bonded PPy films with embedded CNTs on diazonium-modified flexible ITO sheets. The scheme also displays the preparation of reference materials, namely PPy-coated bare ITO and diazonium-modified ITO. 


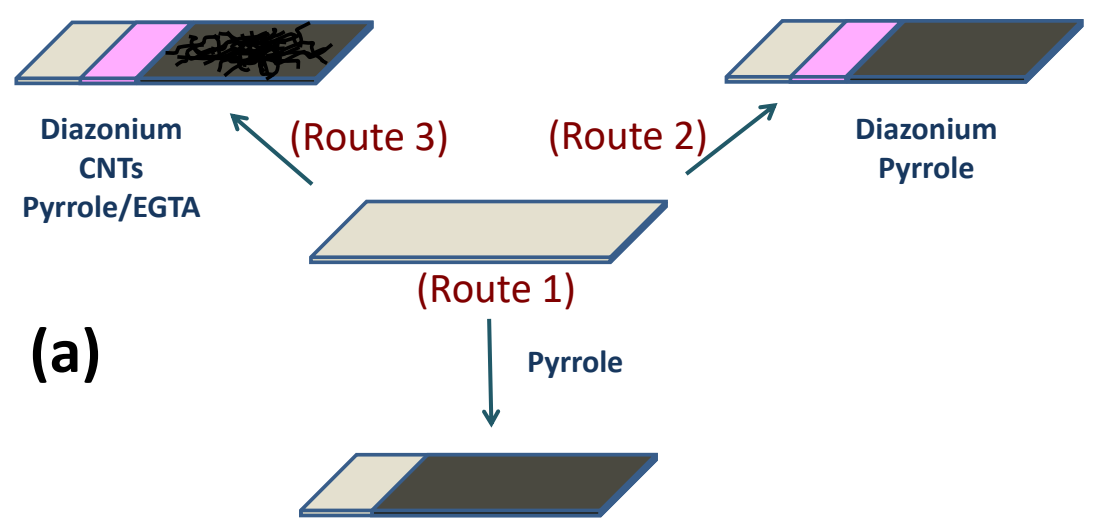<smiles>O=C(O)CN(CCOCCOCCN(CC(=O)O)CC(=O)O)CC(=O)O</smiles>

Scheme 1. (a) Procedure for electrodeposition of polypyrrole on bare ITO (Route 1), $\mathrm{NH}_{2}$ ITO (Route 2), and CNT/NH $2-$ ITO in the presence of EGTA (Route 3), the structure of which is shown in (b).

Figures $1 \mathrm{~A}-\mathrm{C}$ represent the $\mathrm{CVs}$ obtained for the electrosynthesis in similar conditions of the PPy/ITO, PPy/NH $\mathrm{N}_{2}$-ITO, and PPy/CNT/NH 2 -ITO films, respectively. Cyclic voltammetry was performed for ten sequential cycles, at a scan rate of $0.1 \mathrm{~V} \mathrm{~s}^{-1}$, in the potential range $(-1.0$ to1.2 V/SCE) in aqueous medium $\sim 20 \mathrm{ml}$ total volume containing $0.01 \mathrm{M}$ of BSA, $0.01 \mathrm{M}$ of EGTA, and $0.03 \mathrm{M}$ of $\mathrm{NaOH}$. The characteristic $\mathrm{CV}$ of pyrrole electropolymerization on bare ITO electrodes (Figure 1A) presents anodic and cathodic peaks at 0.34 and $-0.25 \mathrm{~V} / \mathrm{SCE}$, respectively. The PPy film, prepared in these conditions on bare ITO, is not adherent and could be easily removed which contrasts with the remarkable adhesion of PPy films prepared on $\mathrm{NH}_{2}$-ITO (Figure 1B). The peak at $\sim+0.35 \mathrm{~V} / \mathrm{SCE}$ corresponds to the oxidation of pyrrole on ITO- $\mathrm{NH}_{2}$ and increases with the number of cycles. The increase in the intensity of the oxidation and reduction peaks (at 0.4 and $-0.12 \mathrm{~V} / \mathrm{SCE}$, respectively) with the number of cycles is consistent with the growth of an electroactive PPy coating [39]. Furthermore, the peak currents have higher intensities for the same system for PPy on a CNT/ $\mathrm{NH}_{2}-\mathrm{ITO}$ surface (Figure 1C). The strongly adherent PPy films on $\mathrm{CNT} / \mathrm{NH}_{2}-\mathrm{ITO}$ surfaces exhibit anodic and cathodic peaks at 0.25 and $-0.85 \mathrm{~V} / \mathrm{SCE}$ which increases with the number of cycles. These differences in electroactivity versus the substrate nature clearly indicate that PPy coating deposited on $\mathrm{CNT} / \mathrm{NH}_{2}$-ITO is the most conductive. These results are in line with those 
reported by Pilan et al. [40] in their study of polyaniline/carbon nanotube composite film electrosynthesis through diazonium salts electroreduction.
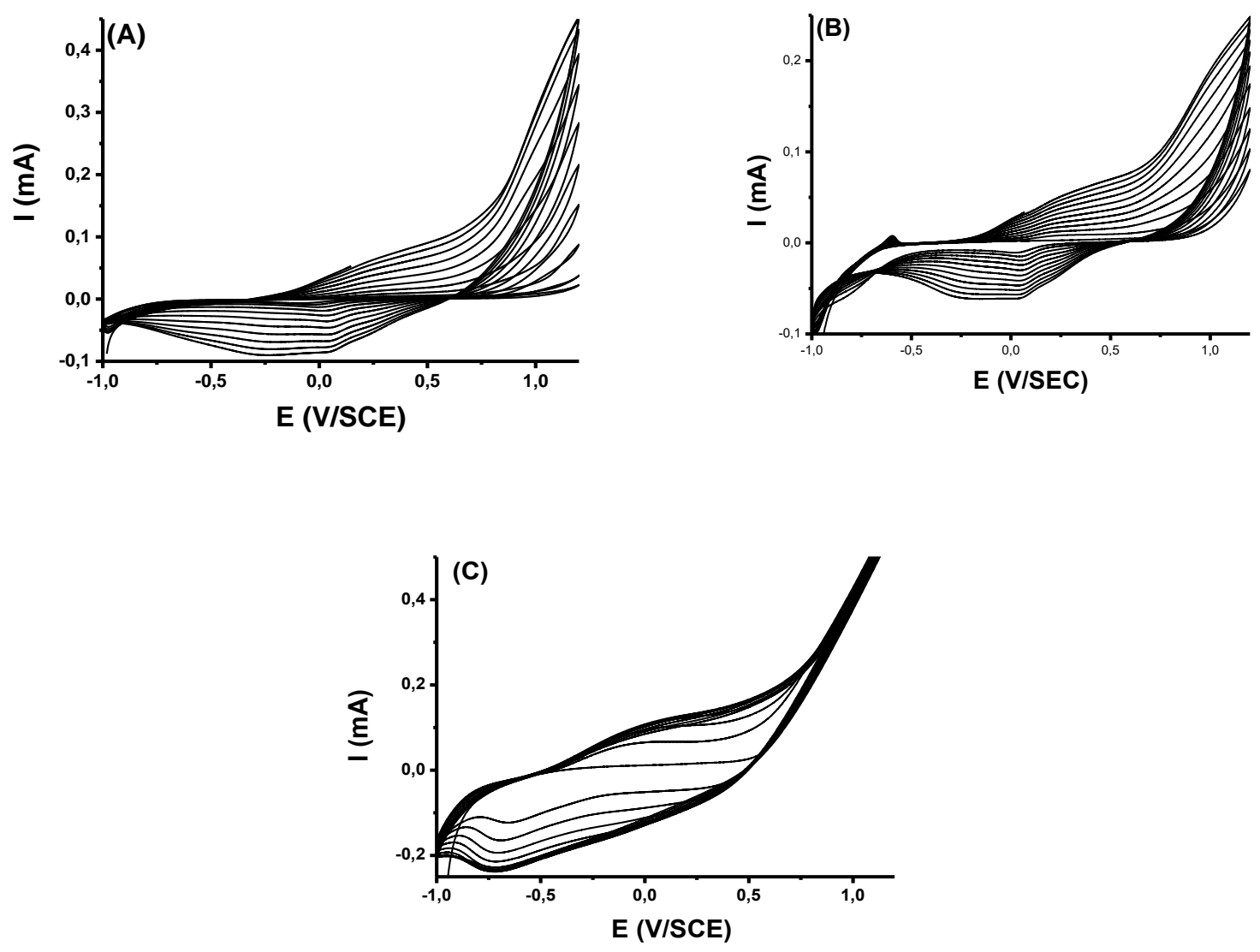

Figure 1. Electropolymerization of PPy on (A) bare ITO, (B) $\mathrm{NH}_{2}-\mathrm{ITO}$, and (C) $\mathrm{CNTs} / \mathrm{NH}_{2}$-ITO.

\subsection{Structural characterization of modified flexible ITO sheets}

\subsubsection{Electrochemical properties}

$\mathrm{Fe}(\mathrm{CN})^{3-/ 4-}$ was used as redox probe to characterize PPy-ITO, PPy/ $\mathrm{NH}_{2}-\mathrm{ITO}, \mathrm{PPy} / \mathrm{CNT} / \mathrm{NH}_{2}-$ ITO by CV and EIS (Figure 2). From CV (Figure 2A), one can extract the potential difference between the anodic and the cathodic peaks, which is high for PPy films deposited on bare ITO: $\Delta \mathrm{E}=\left|\mathrm{E}_{\text {red }}-\mathrm{E}_{\text {ox }}\right|=430 \mathrm{mV}$.

This difference can be linked to the absence of any adhesion between the PPy layer and the bare ITO surface [28]. In the case of PPy/ $\mathrm{NH}_{2}$-ITO, the presence of $-\mathrm{NH}_{2}$ on ITO contributes to increase the electronic transfers leading to a lower $\Delta \mathrm{E}(181 \mathrm{mV})$. For PPy/CNT/NH $2-\mathrm{ITO}$, $\Delta \mathrm{E}=321 \mathrm{mV}$. The CVs are consistent with those obtained by EIS (Figure 2B). Indeed, EIS 
shows a low resistivity in the case of $\mathrm{PPy} / \mathrm{CNT} / \mathrm{NH}_{2}$-ITO, a significant blocking effect (increase of Rct) in the case of PPy-ITO, and a decrease of the resistivity character in the case PPy/ $/ \mathrm{NH}_{2}$-ITO. The following Rct values were obtained: 2250, 690 and $445 \mathrm{Ohms}$ for $\mathrm{PPy} / \mathrm{ITO}, \mathrm{PPy} / \mathrm{NH}_{2}$-ITO and PPy/CNT/NH $2-\mathrm{ITO}$, respectively.

The equivalent circuit diagram is shown in the inset of Figure 2B; it fits the three electrodes. It includes a charge transfer resistor (Rtc) describing the response of the film at high frequencies. The capacity of the electric double layer $(\mathrm{Cd})$ takes into account the parasitic capacity of the ITO substrate. The circuit also contains an additional resistance $(\mathrm{Re})$ in series with these elements which describes the resistance of the electrolytic medium. Finally, the constant phase element $(\mathrm{Zw})$ in series with the film components describes the behavior of the ion blocking system near the electrodes.

From the above, the presence of a PPy layer on CNT/ $\mathrm{NH}_{2}-\mathrm{ITO}$ surface leads to an increase of electronic transfers due to the presence of the CNTs in the layer.
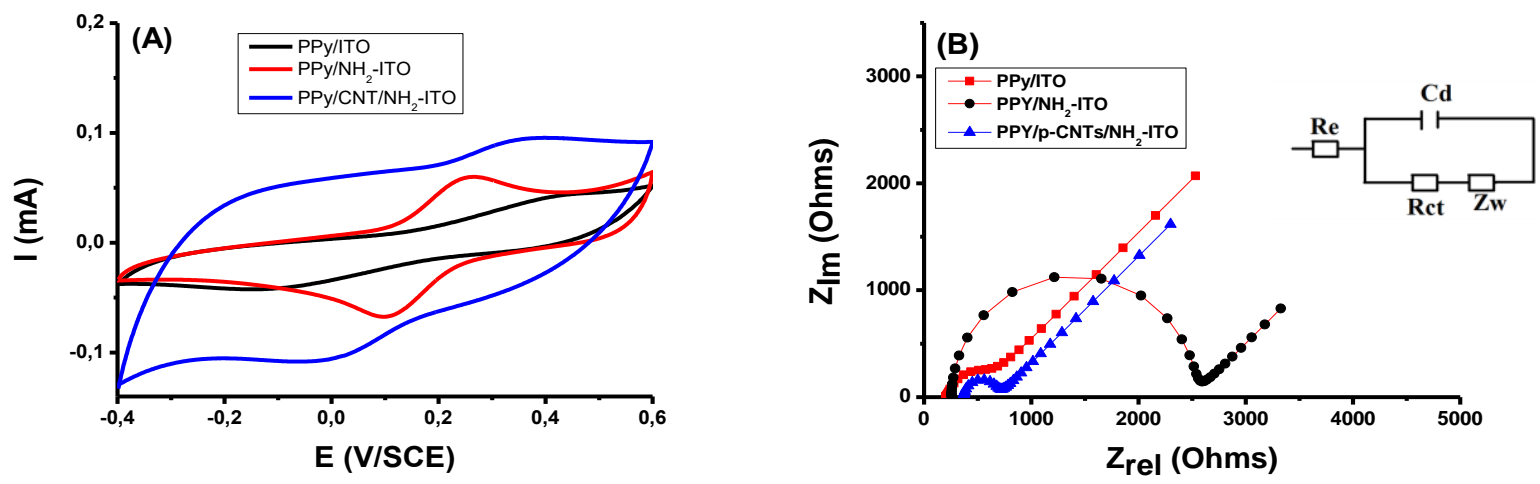

Figure 2. (A) Cyclic voltammograms, and (B) Nyquist plots of electrochemical impedance spectra obtained for PPy-ITO, PPy/NH $\mathrm{NH}_{2}-\mathrm{ITO}, \mathrm{PPy} / \mathrm{CNTs} / \mathrm{NH}_{2}-\mathrm{ITO}$. For CV: scan rate of 50 $\mathrm{mV} \mathrm{s}^{-1}$; for EIS: within the frequency range of $100 \mathrm{mHz}-10 \mathrm{kHz}$. Inset of Figure 2B displays the equivalent circuit. $\mathrm{Cd}$ : double layer capacitance; Rct: Charger transfer resistance; $\mathrm{Zw}$ : Warburg resistance; Re : resistance of the solution.

\subsubsection{Raman study of modified flexible ITO sheets}

Figure 3 shows the Raman spectra of $\mathrm{NH}_{2}-\mathrm{ITO}, \mathrm{CNT} / \mathrm{NH}_{2}$-ITO and PPy/CNT/NH $2-\mathrm{ITO}$. The $\mathrm{NH}_{2}$-ITO sample exhibits Raman bands due to the aryl groups, centered at 1387 and 1632 $\mathrm{cm}^{-1}$, assigned respectively to the $\mathrm{C}-\mathrm{H}$ and $\mathrm{C}=\mathrm{C}$ bonds in benzene ring. The band located at 
$1104 \mathrm{~cm}^{-1}$ is assigned to $\mathrm{C}-\mathrm{H}$ in-plane vibrations and the band at $1282 \mathrm{~cm}^{-1}$ is due to the $\mathrm{C}-\mathrm{N}$ stretching vibration [41].

The Raman spectra of CNTs deposited on the aryl diazonium layer show the most prominent features, i.e. the D band, associated with the defects in the hexagonal graphitic layers, and the $\mathrm{G}$ band, related to the vibrations of $\mathrm{sp}^{2}$-bonded carbon atoms in a two-dimensional hexagonal lattice. The $\mathrm{D}$ and $\mathrm{G}$ bands are centered at 1337 and $1587 \mathrm{~cm}^{-1}$, respectively, with the ID/IG peak intensity ratio of 1.21 for $\mathrm{CNT} / \mathrm{NH}_{2}$-ITO. These results suggest that the surface treatment with the aryl diazonium salt does not affect the structure of the CNTs [17] and confirm that the aryl groups are interacting with CNTs via van der Waals interactions and $\mathrm{H}$ bonding.

$\mathrm{PPy} / \mathrm{CNT} / \mathrm{NH}_{2}$-ITO surface exhibits a band at $1332 \mathrm{~cm}^{-1}$ attributed to the ring-stretching mode of PPy, whereas the peak at $1566 \mathrm{~cm}^{-1}$ is assigned to the backbone stretching mode of $\mathrm{C}=\mathrm{C}$ bonds with the ID/IG peak intensity ratio 1.05 [42]. The Raman spectrum of $\mathrm{PPy} / \mathrm{CNT} / \mathrm{NH}_{2}-\mathrm{ITO}$ is similar to that obtained by Song et al. [42] and reveals that CNTs serve as the core in the formation of PPy/CNT composite.

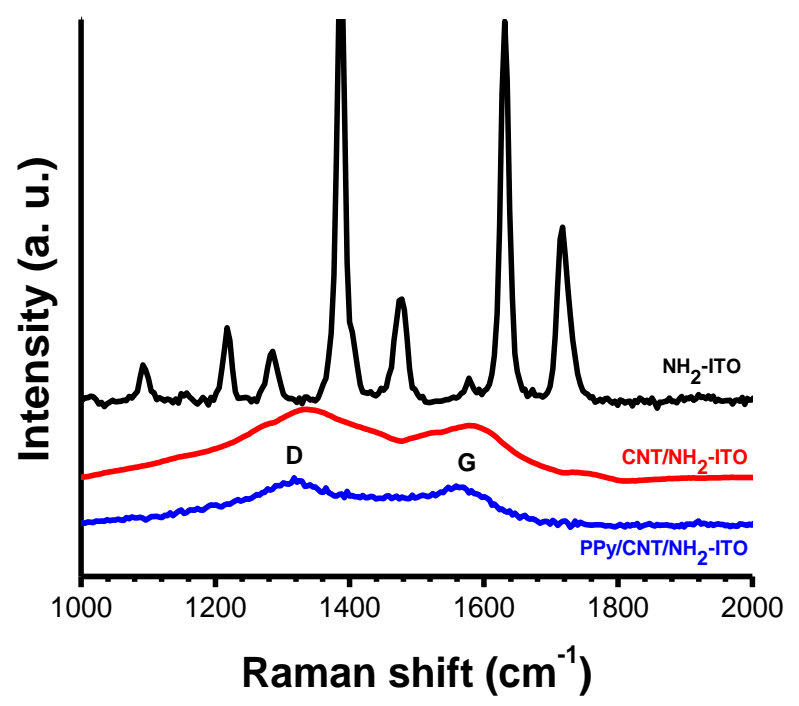

Figure 3. Raman spectra of $\mathrm{NH}_{2}-\mathrm{ITO}, \mathrm{CNT} / \mathrm{NH}_{2}-\mathrm{ITO}, \mathrm{PPy} / \mathrm{CNT} / \mathrm{NH}_{2}-\mathrm{ITO}$.

\subsubsection{Morphology of modified flexible ITO sheets}

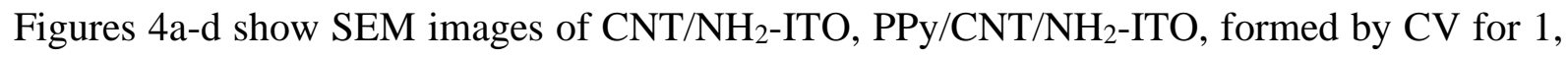
5 and 10 cycles. The SEM images of areas filled with CNTs (Fig. 4a) further demonstrate that the tubes are homogeneous and can be distinguished individually with a nanometer scale 
width. In Figure 4b, the SEM images of PPy on CNT/NH $2-I T O$ formed after one CV does not change the arrangement of CNTs, but preferentially wraps around them, one by one. When the number of cycles increases to 5 (Figure 4c) and 10 (Figure 4d), the CNTs thicken gradually and homogeneously due to the wrapping by PPy. For 10 voltammetric cycles, $\mathrm{PPy} / \mathrm{CNT} / \mathrm{NH}_{2}-\mathrm{ITO}$ exhibits compact filaments with persisting three-dimensional porous microstructure [43]. Interestingly, there is no side deposition of PPy indicating that the electrosynthesis of the polymer is confined to the sidewalls of the nanotubes, therefore suggesting strong interactions between PPy and the underlying CNTs.

CNTs diameter distributions for 0, 1,5 and $10 \mathrm{CVs}$ of PPy electrodeposition are shown in the insets of Figures 4A-D. The CNT average diameter is $18 \pm 2.6 \mathrm{~nm}$ (Figure 4A), then increases to $27 \pm 4.8,35.6 \pm 5.9$ and $175 \pm 20.1$ after 1,5 and 10 of electropolymerization of pyrrole (Figures 4B-D). The descriptive statistics are reported in Table 1. The SEM results confirm that the deposition of PPy is mostly confined to the CNT sidewalls.

Table 1. Average CNT diameters and descriptive statistics summary

\begin{tabular}{|c|c|c|c|c|c|}
\hline \multirow[t]{2}{*}{ Sample } & Mean & $\begin{array}{c}\text { Standard } \\
\text { Deviation }\end{array}$ & Median & Minimum & Maximum \\
\hline & $(\mathrm{nm})$ & $(\mathrm{nm})$ & $(\mathrm{nm})$ & $(\mathrm{nm})$ & $(\mathrm{nm})$ \\
\hline $\mathrm{CNT} / \mathrm{NH}_{2}$-ITO & 18.0 & 2.6 & 17.9 & 11.0 & 24.8 \\
\hline $\begin{array}{l}\mathrm{PPy} / \mathrm{CNT} / \mathrm{NH}_{2} \text {-ITO } \\
\text { formed by } \mathrm{CV} \text { for } 1 \text { cycle }\end{array}$ & 27.0 & 4.8 & 26.1 & 19.8 & 46.5 \\
\hline $\begin{array}{l}\mathrm{PPy} / \mathrm{CNT} / \mathrm{NH}_{2}-\mathrm{ITO} \\
\text { formed by } \mathrm{CV} \text { for } 5 \text { cycles }\end{array}$ & 35.6 & 5.9 & 34.6 & 25.1 & 63.0 \\
\hline $\begin{array}{l}\mathrm{PPy} / \mathrm{CNT} / \mathrm{NH}_{2}-\mathrm{ITO} \\
\text { formed by } \mathrm{CV} \text { for } 10 \text { cycles }\end{array}$ & 175.0 & 20.1 & 176.5 & 126.3 & 233.0 \\
\hline
\end{tabular}

The interface between CNTs and $\mathrm{NH}_{2}$-ITO has been imaged by SEM (Figure 5). The attachment of CNTs on the $\mathrm{NH}_{2}$-ITO surface can be noted (Figures 5a-b), thus proving the interaction of the carbon nanotubes and diazonium-modified ITO [44,45]. The SEM morphology for the interface between PPy and CNT/NH2-ITO (Figure 5c) shows that PPy is wrapped around the CNTs [40] therefore confirming the structures displayed in Figure 4. 

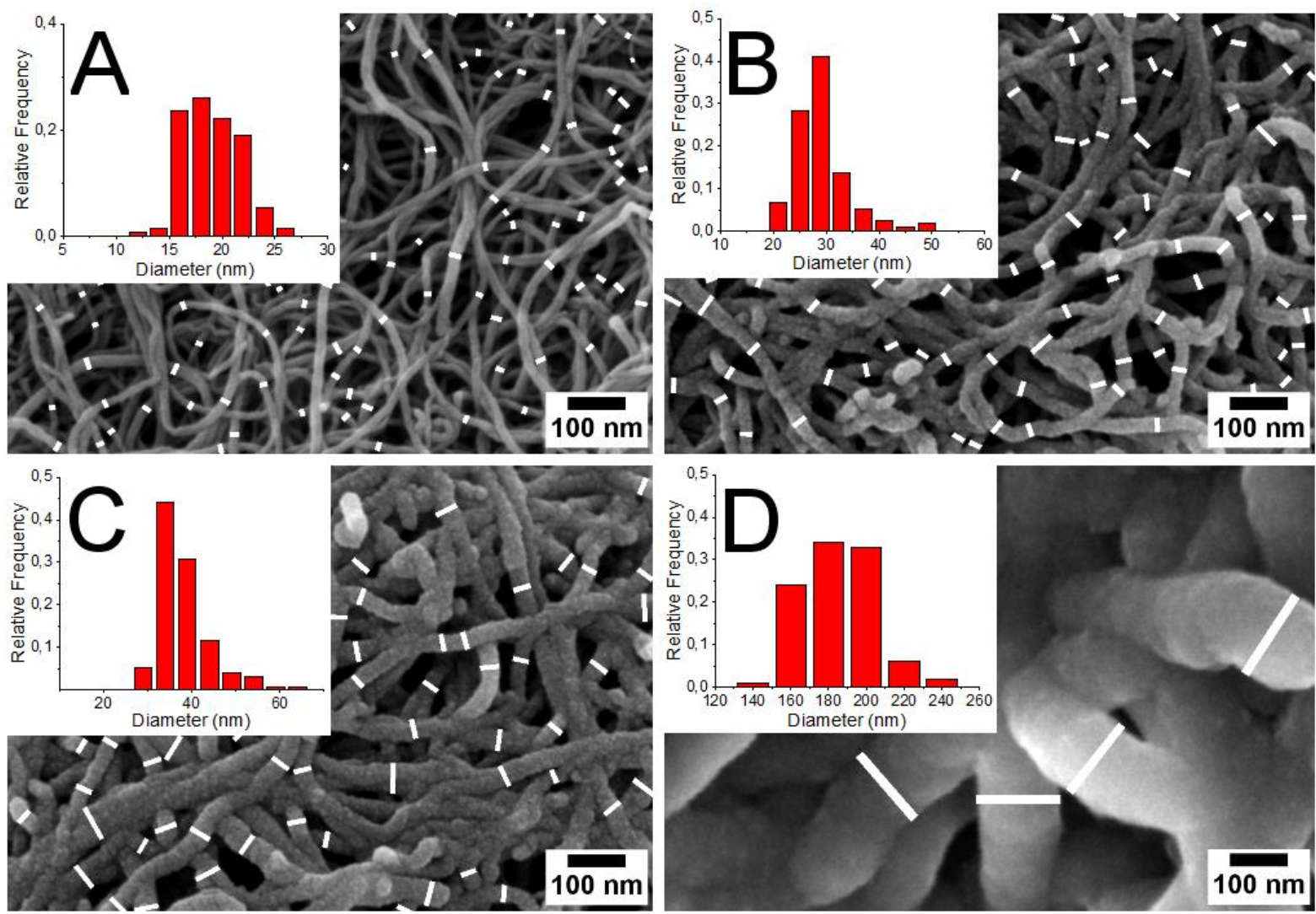

Figure 4. CNT size distribution. Histogram of the relative frequency versus the CNT diameters determined. (A) $\mathrm{CNT} / \mathrm{NH}_{2}$-ITO, (B) PPy/CNT/NH $\mathrm{N}_{2}$-ITO formed by CV for 1 cycle, (C) $\mathrm{PPy} / \mathrm{CNT} / \mathrm{NH}_{2}$-ITO formed by $\mathrm{CV}$ for 5 cycles, (D) PPy/CNT/ $\mathrm{NH}_{2}$-ITO formed by $\mathrm{CV}$ for 10 cycles. 


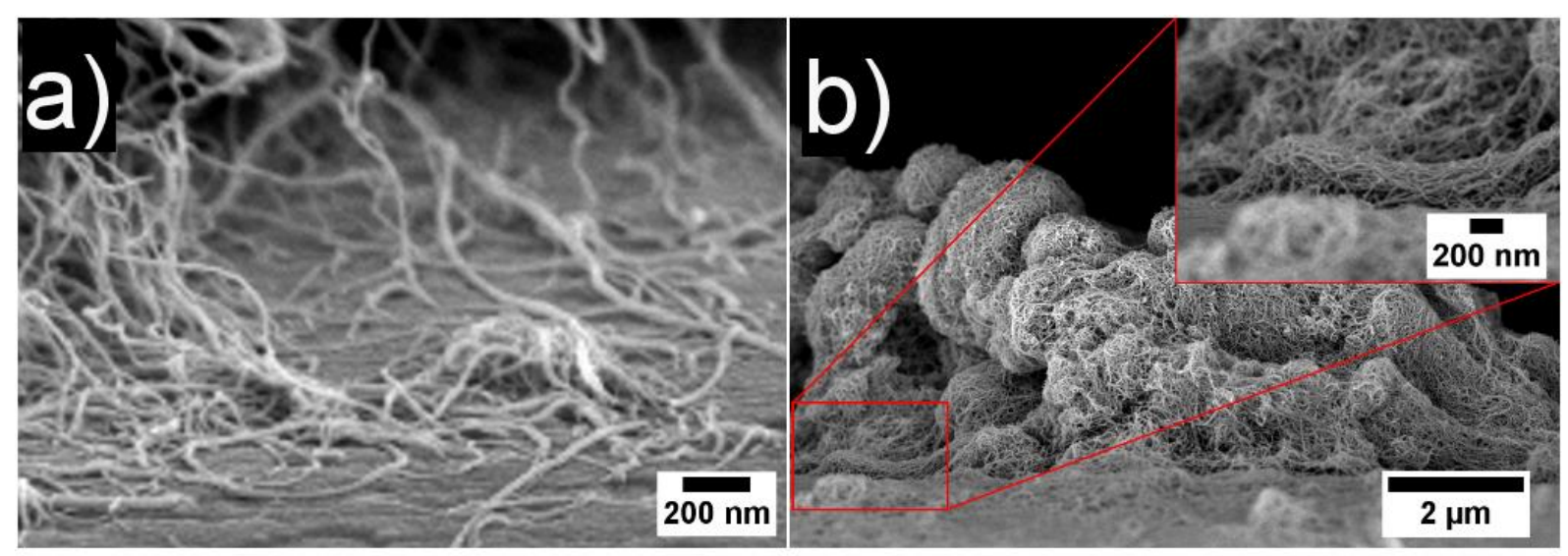

\section{c)}

CNT@PPy-EGTA

\section{$\mathrm{NH}_{2}$-ITO}

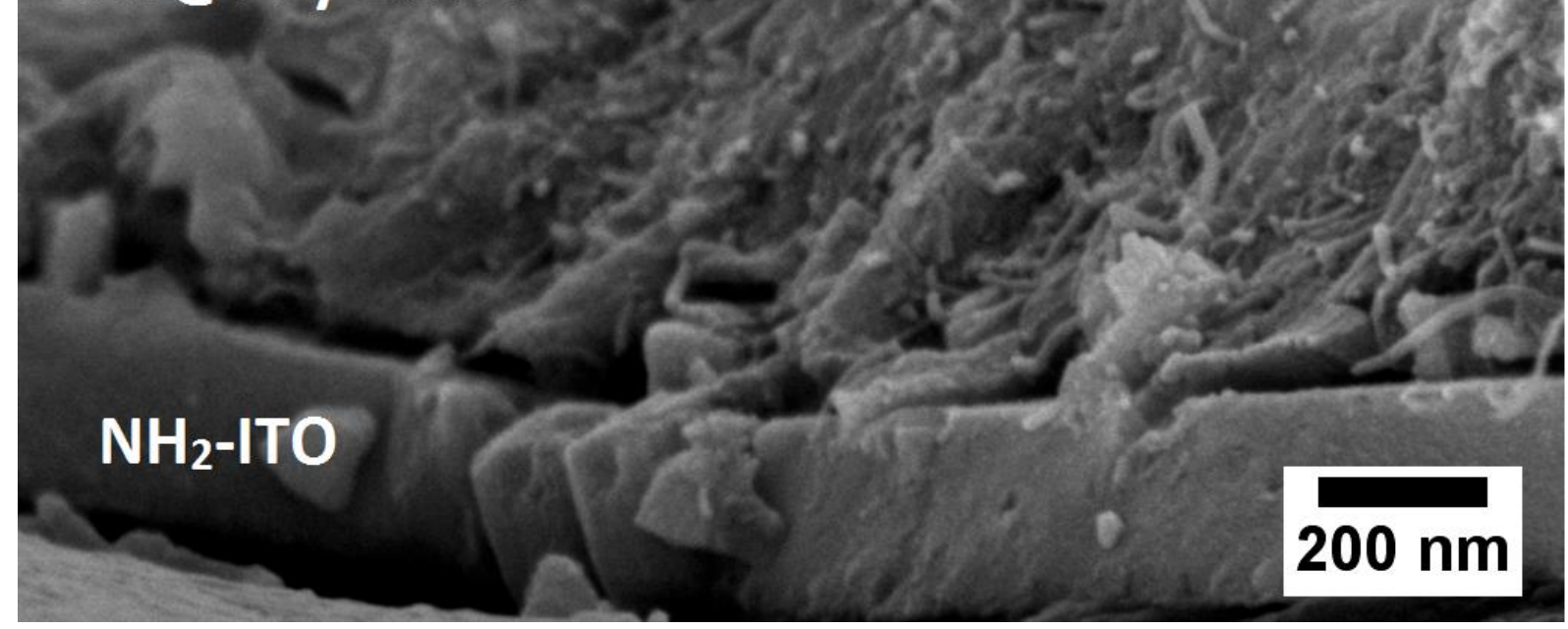

Figure 5. SEM images of (a) interface between CNTs and $\mathrm{NH}_{2}-\mathrm{ITO}$ at high magnification (scale bar $200 \mathrm{~nm}$ ) and (b) low magnification (scale bar $2 \mu \mathrm{m}$ ), (c) Interface between PPywrapped CNTs and $\mathrm{NH}_{2}$-ITO at high magnification (scale bar $200 \mathrm{~nm}$ ). Inset of (b) shows front view of the cross-section at high magnification (scale bar $200 \mathrm{~nm}$ ).

\subsubsection{XPS surface analysis}

We have previously reported the surface analysis of bare ITO and $\mathrm{NH}_{2}$-ITO electrodes $[28,29,31]$. Herein, we concentrate on $\mathrm{CNT} / \mathrm{NH}_{2}-\mathrm{ITO}$ and PPy/CNT/ $\mathrm{NH}_{2}-\mathrm{ITO}$ surfaces. Figure 6 displays survey, $\mathrm{C} 1 \mathrm{~s}, \mathrm{~N} 1 \mathrm{~s}$ and $\mathrm{S} 2 \mathrm{p}$ spectra recorded for $\mathrm{CNT} / \mathrm{NH}_{2}-\mathrm{ITO}$ and $\mathrm{PPy} / \mathrm{CNT} / \mathrm{NH}_{2}$-ITO. Figure 6a shows neat surface with $\mathrm{C} 1 \mathrm{~s}$ from CNTs on ITO with low $\mathrm{C} 1 \mathrm{~s}$ relative peak intensity, whilst $\mathrm{C} 1 \mathrm{~s}$ and N1s get much more intense after PPy coating (Figure 
$6 b$ ). The ITO is still visible (In $3 \mathrm{~d}$ at $445 \mathrm{eV}$ ) due to the porous nature of the sensing layer (see SEM Figures $4 b-c)$. Nevertheless, the inelastic background exhibited in Figure $6 b$ is in line with ITO substrate screened by the PPy/CNT top layer. Concerning the narrow $\mathrm{C} 1 \mathrm{~s}$ regions (Figures 6c,d), it is clear that the shape changes significantly due to PPy; the broad spectrum has contributions from the carbon atoms in $\alpha$ and $\beta$ positions to the nitrogen from pyrrole ring [46]. Most probably, the shoulder noted at $\sim 288.8 \mathrm{eV}$ accounts for COO groups from EGTA. $\mathrm{N} 1 \mathrm{~s}$ peak from $\mathrm{CNT} / \mathrm{NH}_{2}$-ITO (Figure 6e) accounts for the aryl adhesive layer, whereas Figure $6 \mathrm{f}$ displays an N1s spectrum that has the shape of that previously reported for polypyrrole [47]. Finally, Figures 6(g,h) indicate that BSA is the only source of sulfur, and that the peak position accounts indeed for sulfur in sulfonate chemical environment.
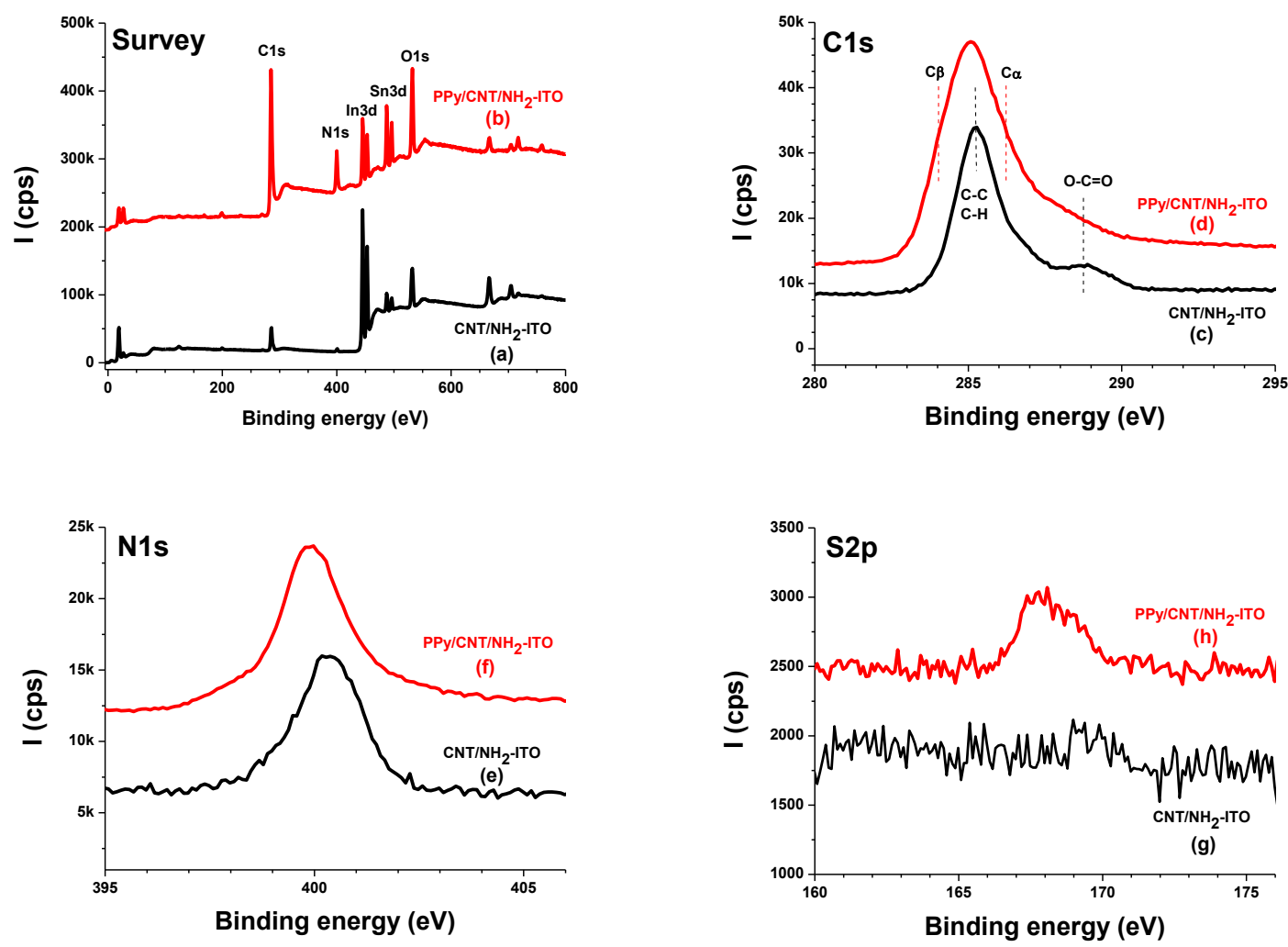

Figure 6. XPS spectra of CNT/NH $\mathrm{N}_{2}-\mathrm{ITO}(\mathrm{a}, \mathrm{c}, \mathrm{e}, \mathrm{g})$ and $\mathrm{PPy} / \mathrm{CNT} / \mathrm{NH}_{2}-\mathrm{ITO}(\mathrm{b}, \mathrm{d}, \mathrm{f}, \mathrm{h})$ : Survey regions (a,b), C1s (c,d), N1s (e,f) and S2p (g,h).

\subsection{Electroanalytical application of PPy/CNT/NH2-ITO electrodes}

The electrochemical response was assessed in the same electrolytic solution containing $10^{-7}$ mol. $\mathrm{L}^{-1}$ of $\mathrm{Pb}^{2+}$, using two different modified electrodes: $\mathrm{PPy} / \mathrm{CNT} \mathrm{NH}_{2}-\mathrm{ITO}$ and 
$\mathrm{PPy} / \mathrm{NH}_{2}$-ITO (Figure 7A). It is worth to note that the peak current obtained for $\mathrm{PPy} / \mathrm{CNT} / \mathrm{NH}_{2}$-ITO presents a higher value than that obtained for PPy/ $\mathrm{NH}_{2}$-ITO due to the conductivity increase imparted by CNTs to the PPy matrix. As reported elsewhere, CNTs might enhance the diffusion rate of heavy metal ions during the sensing measurements [48]. The effect of pre-concentration time on the DPV current is displayed in Figure 7B. The stripping peak current for both metals increased with the pre-concentration time up to $10 \mathrm{~min}$. For periods longer than $10 \mathrm{~min}$, the peak current was almost constant, which might be due to the electrode saturation by $\mathrm{Pb}^{2+}$. Therefore, the value of 10 min was chosen as the preconcentration time.

$\mathrm{PPy} / \mathrm{CNT} / \mathrm{NH}_{2}$-ITO samples served to detect lead ions in an aqueous medium by differential pulse voltammetry (DPV) (Figure 7C). This figure displays DPV signals for $\mathrm{Pb}^{2+}$ concentrations in the $10^{-8}$ to $3 \times 10^{-7} \mathrm{~mol} . \mathrm{L}^{-1}$ range $(\mathrm{I}(\mu \mathrm{A})=1.5 \mathrm{C}+1.64, \mathrm{R}=0.996)$. $\mathrm{LOD}$ is deduced from the DPV peak intensity- $v s$-concentration correlation (Fig. 7D); LOD $=2.9 \times 10^{-9}$ mol.. $\mathrm{L}^{-1}$ and the limit of quantification $\mathrm{LOQ}=8.7 \times 10^{-9} \mathrm{~mol} \cdot \mathrm{L}^{-1}$ at $\mathrm{S} / \mathrm{N}=3$. It is worth to note that the actual LOD is lower than that reported for EDTA-functionalized polypyrrole $(0.1$ ppm) [33] and for EDTA-PPy/SWNTs nanocomposite $\left(70 \times 10^{-9} \mathrm{~mol}_{\mathrm{L}}^{-1}\right)$ [34]. 


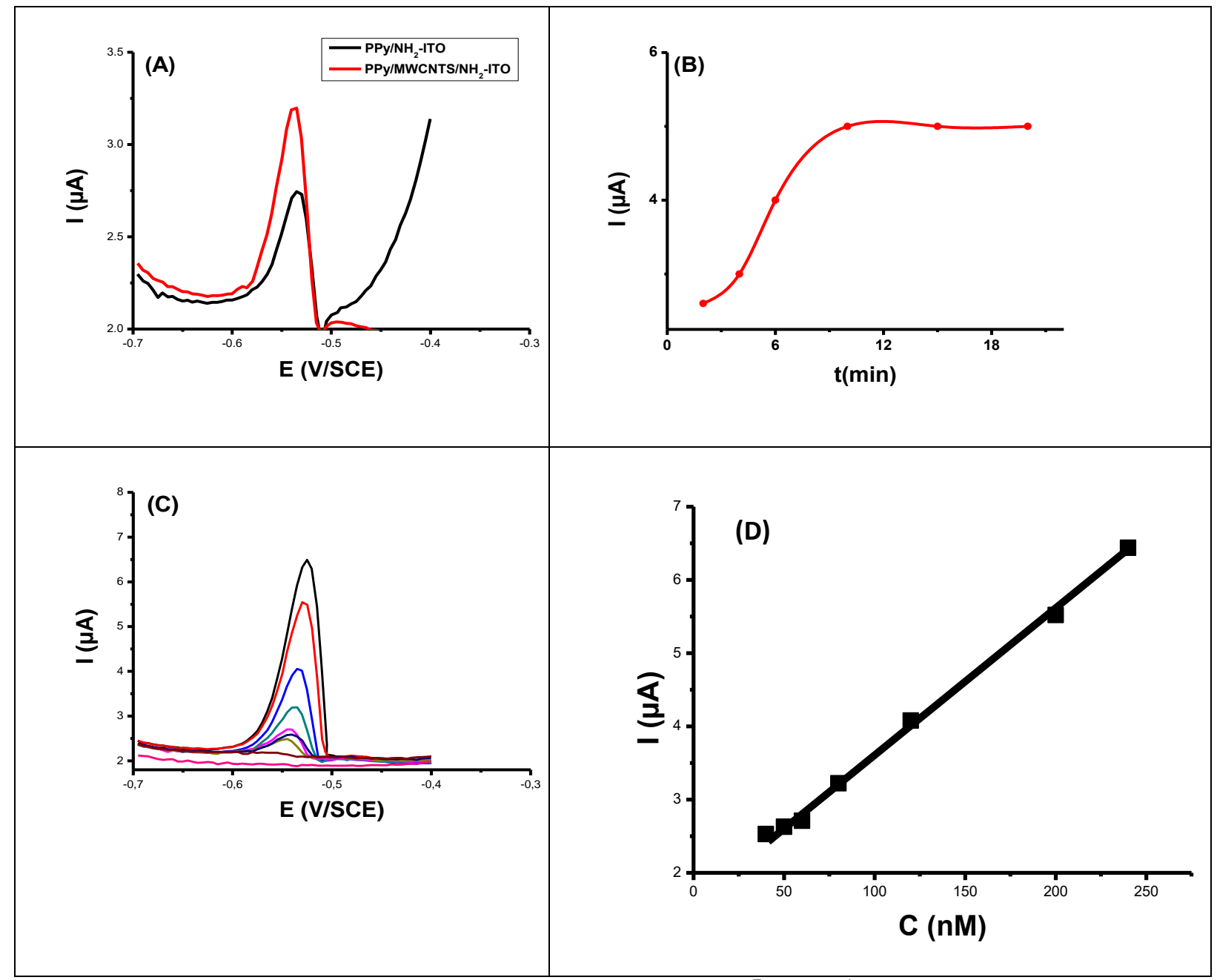

Figure 7. (A) DPV of $\mathrm{Pb}(\mathrm{II})$ at $\mathrm{pH} 5$ containing $\mathrm{Pb}(\mathrm{II}) 10^{-7} \mathrm{~mol} . \mathrm{L}^{-1}$ for $\mathrm{PPy} / \mathrm{CNT} / \mathrm{NH}_{2}-\mathrm{ITO}$ and $\mathrm{PPy} / \mathrm{NH}_{2}-\mathrm{ITO}$, (B) Time effect of pre-concentation metal ion on PPy/CNT/ $/ \mathrm{NH}_{2}-\mathrm{ITO}$, (C) $\mathrm{Pb}$ (II) stripping peak vs $\mathrm{Pb}$ (II) concentration in the $10^{-8}-2.5 \times 10^{-7} \mathrm{~mol} . \mathrm{L}^{-1}$ range. (D) Calibration curve for the detection of $\mathrm{Pb}$ (II) using $\mathrm{PPy} / \mathrm{CNT} / \mathrm{NH}_{2}-\mathrm{ITO}$ electrode.

At this stage, the question concerning the use of EGTA remains open: how useful is this chelator? Previously, we have shown that without any CNTs and EGTA, the LOD is $\sim 1 \times 10^{-9} \mathrm{~mol} . \mathrm{L}^{-1}$, which is slightly better. However, with CNTs, a better conductivity of the sensing top layer is obtained. Concerning EGTA, we have investigated the selectivity of the film towards $\mathrm{Pb}^{2+}$ and $\mathrm{Cu}^{2+}$. According to our previously published procedure [31], we have determined, for a total initial concentration of metal ions of $2.5 \times 10^{-6} \mathrm{~mol} . \mathrm{L}^{-1}$, the relative intensity of $\mathrm{Pb}^{2+}$ stripping peak, in the presence and in the absence of interfering $\mathrm{Cu}^{2+}$ ions, at various initial $\mathrm{Cu}^{2+} / \mathrm{Pb}^{2+}$ molar ratio. The electrochemical response is displayed in Figure 8. As it can be seen, there are two well resolved stripping peaks assigned to $\mathrm{Pb}^{2+}$ and to $\mathrm{Cu}^{2+}$, 
respectively. Inset of Figure 8 plots the $\mathrm{Pb}$ peak intensity ratio $\mathrm{I}_{\mathrm{s}} / \mathrm{I}_{0}$ (in $\%$ ), where $\mathrm{I}_{\mathrm{s}}$ and $\mathrm{I}_{0}$ stand for the stripping peak of $\mathrm{Pb}^{2+}$ in the presence and absence of $\mathrm{Cu}^{2+}$ interfering cations, respectively. Obviously, with EGTA, despite the presence of $\mathrm{Cu}^{2+}$, the stripping response of $\mathrm{Pb}^{2+}$ does not decrease significantly, hence the interest of co-doping PPy with the EGTA chelator.

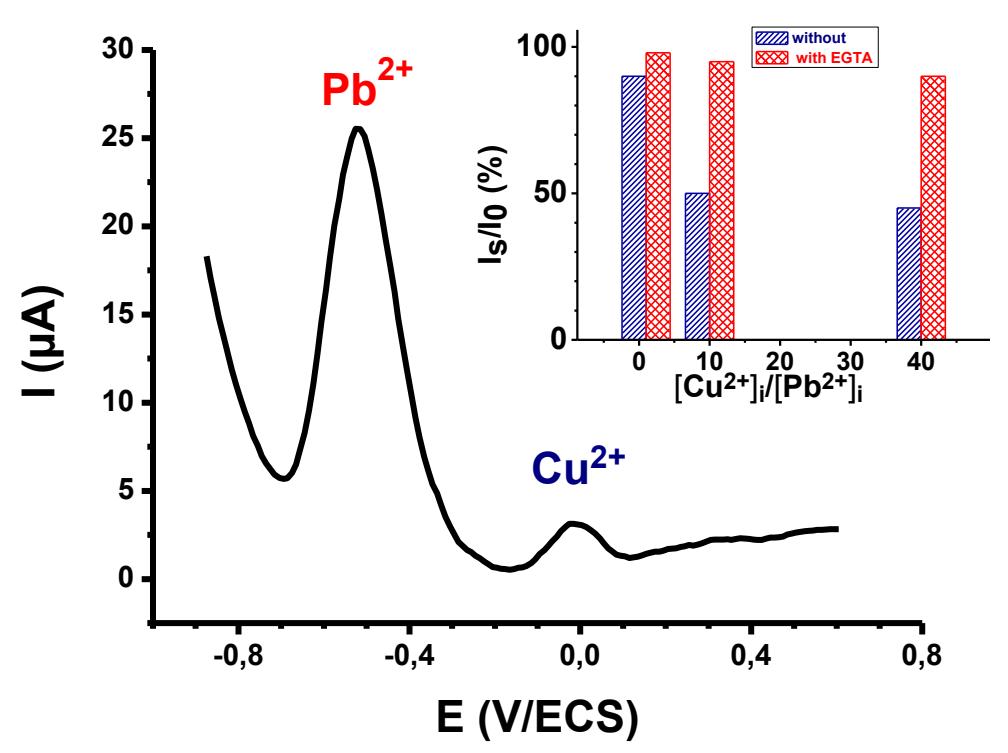

Figure 8. DPV simultaneous determination of concentration $2.510^{-6} \mathrm{M}$ of a $\mathrm{Pb}^{2+}$ and $\mathrm{Cu}^{2+}$ mixture with initial $\mathrm{Cu}^{2+} / \mathrm{Pb}^{2+}$ molar ratio $=1$. Inset shows that for $\left[\mathrm{Cu}^{2+}\right]_{i} /\left[\mathrm{Pb}^{2+}\right]_{i}=1,10,40$, $I_{s} / I_{0}=90,50$ and 45, respectively, without EGTA; whilst $I_{s} / I_{0}=98,95$ and 90 , respectively, in the presence of EGTA.

\subsection{Density functional theory calculations}

Quantum chemical calculations were performed using density functional theory (DFT) at B3LYP/6-31+G* level. The 6-311+G(d) basis set was used for H, C, N, O atoms and LANL2DZ basis set for $\mathrm{Cu}$ and $\mathrm{Pb}$ atoms as implemented in Gaussian16 [49,50].

The solvent effect was added by using the United Atom molecular cavity model UAKS (united atom Kohn-Sham model) [51]. The formation energy of the complexes in gas phase and in solvent was computed from Hess thermodynamic cycle (Scheme 2). The gas phase ionization energy was extracted from reference [52]. 
a)

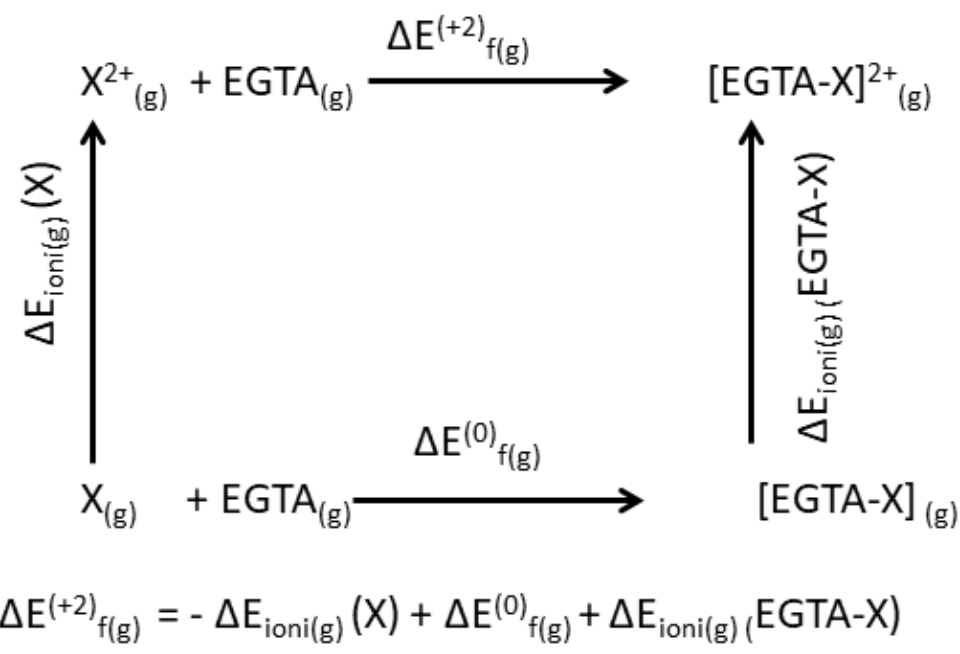

b)

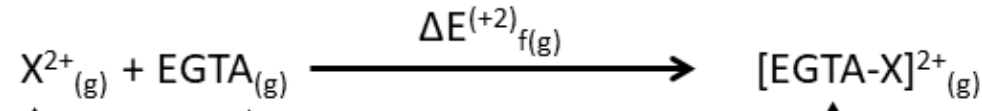

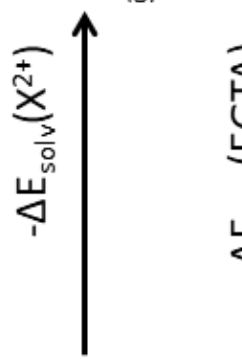

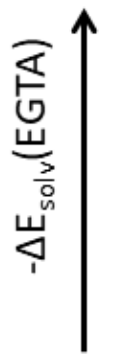

$\mathrm{X}^{2+}{ }_{\text {solv }}+\mathrm{EGTA}_{\text {solv }}$

$\Delta \mathrm{E}^{(+2)} \mathrm{f(solv)}$

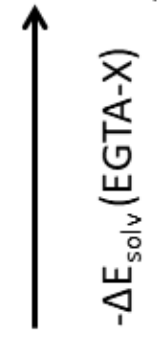

$\Delta \mathrm{E}^{(+2)}{ }_{\mathrm{f}(\text { solv })}=-\Delta \mathrm{E}_{\text {solv }}\left(\mathrm{X}^{2+}\right)-\Delta \mathrm{E}_{\text {solv }}(\mathrm{EGTA})+\Delta \mathrm{E}^{(+2)}{ }_{\mathrm{f}(\mathrm{g})}+\Delta \mathrm{E}_{\text {solv }}(\mathrm{EGTA}-\mathrm{X})$

Scheme 2. Termodynamic cycles used to calculate the complexation energy in gas (a) and in solvent (b).

An exhaustive conformational search was explored for EGTA molecule in order to determine the most stable structure. The most stable configuration is stabilized by hydrogen bonds between carboxylic acid groups as it can be seen in Figure 9. This conformer is used to complex with $\mathrm{Cu}^{2+}$ and $\mathrm{Pb}^{2+}$ ions. The formed complexes are fully optimized and the formation energies are computed in both gas and liquid phases. In gas phase, the calculated complexation energy was found to be $-802.4 \mathrm{~kJ} / \mathrm{mol}$ and $-741.9 \mathrm{~kJ} / \mathrm{mol}$ for $\mathrm{Pb}^{2+}$ and $\mathrm{Cu}^{2+}$, respectively. When adding solvent effect, the values decrease to -374.6 and $-116.4 \mathrm{~kJ} / \mathrm{mol}$ for $\mathrm{Pb}^{2+}$ and $\mathrm{Cu}^{2+}$, respectively. The difference is linked to the more favorable complexation in the gas phase of $\mathrm{Pb}^{2+}$ and the important solvation of $\mathrm{Cu}^{2+}$ (Table 2). Based on these thermodynamics results, one can conclude that the formation of $\mathrm{Pb}^{2+}$ complex is more favorable compared to $\mathrm{Cu}^{2+}$. The optimized geometries of complexes are displayed in Figure 9 and show different types of coordination for the two metal ions. The $\mathrm{Pb}^{2+}$ ion is 
hexa-coordinated with four $\mathrm{O}-\mathrm{Pb}$ bonds, the length of which varying between 2.452 and 2.662 $\AA$, i.e. close the sum of $\mathrm{Pb}$ and $\mathrm{O}$ atomic radii $(2.44 \AA)$. It is bonded to nitrogen atoms at distances of 2.854 and $2.903 \AA$, larger than the sum of atomic radii of isolated elements. The $\mathrm{Cu}^{2+}$ ion is penta-coordinated with four oxygen and one nitrogen atoms. The bond length of $\mathrm{Cu}-\mathrm{O}$ varies between 2.04 and $2.23 \AA$, close to the sum of the atomic radii of $\mathrm{Cu}$ and $\mathrm{O}(2.01$ $\AA$ ). The $\mathrm{Cu}-\mathrm{N}$ bond length is $2.13 \AA$, larger than the sum of the atomic radii of $\mathrm{Cu}$ and $\mathrm{N}(2.03$ A).

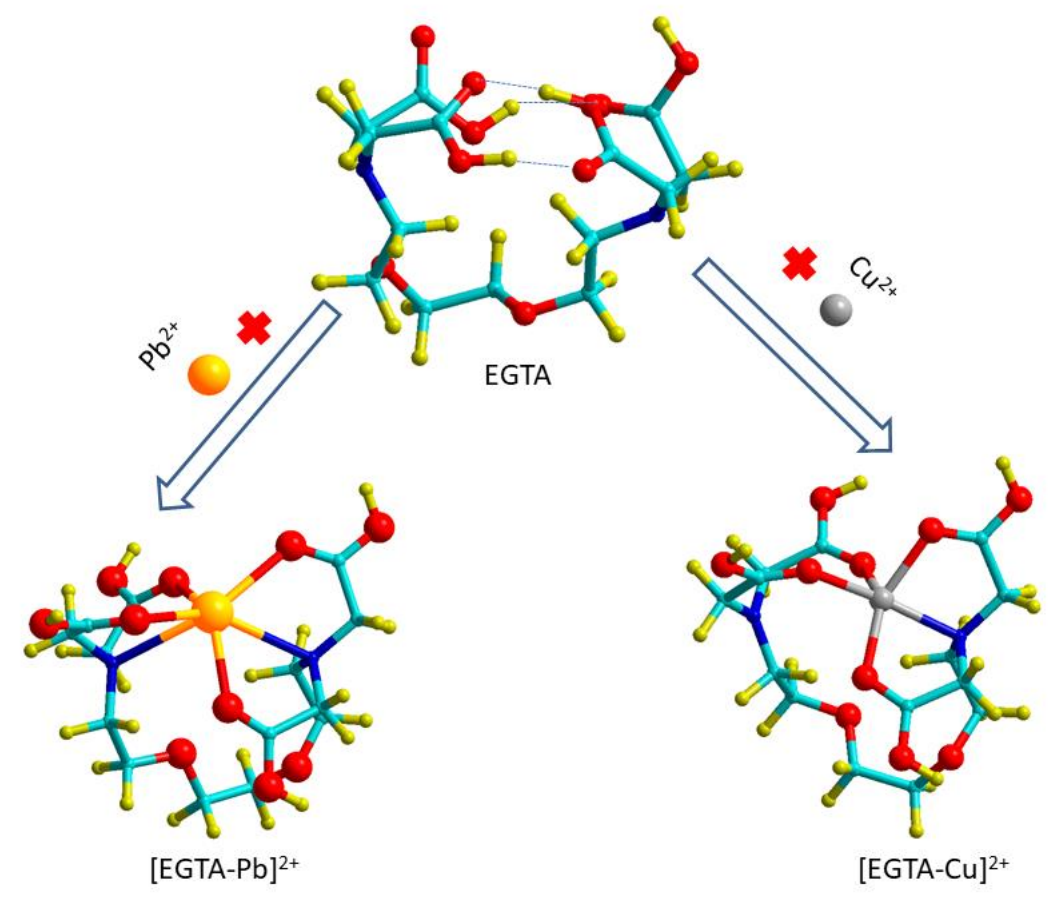

Figure 9. Structures of stable conformers of EGTA and, [EGTA-Pb $]^{2+}$ and $[\text { EGTA-Cu }]^{2+}$ complexes.

Table 2. Formation energies in gas phase $\left(\Delta \mathrm{E}^{(+2)} \mathrm{f}(\mathrm{g})\right)$, in solvent $\left(\Delta \mathrm{E}^{(+2)} \mathrm{f(solv)}\right)$, solvation energies and $\mathrm{X}-\mathrm{O}$ and $\mathrm{X}-\mathrm{N}$ minimum and maximum distances for the most stable complexes.

\begin{tabular}{lccccc}
\hline System & $\Delta \mathrm{E}^{(+2)} \mathrm{f}_{\mathrm{g} g}$ & $\Delta \mathrm{E}_{\text {solv }}$ & $\Delta \mathrm{E}^{(+2)} \mathrm{f(solv}$ & $\mathrm{dX}-\mathrm{O}(\AA)$ & $\mathrm{dX}-\mathrm{N}(\AA)$ \\
\cline { 2 - 6 } & $(\mathrm{kJ} / \mathrm{mol})$ & $(\mathrm{kJ} / \mathrm{mol})$ & $(\mathrm{kJ} / \mathrm{mol})$ & & \\
\hline EGTA & - & -127.8 & - & - & - \\
$\mathrm{Cu}^{2+}$ & - & -1288.8 & - & - & - \\
$\mathrm{Pb}^{2+}$ & - & -1038.8 & - & - & - \\
{$[\text { EGTA-Cu}]^{2+}$} & -741.9 & -790.9 & -116.4 & $2.047(2.238)$ & $2.135(3.574)$ \\
{$\left[\right.$ EGTA-Pb] ${ }^{2+}$} & -802.4 & -738.8 & -374.6 & $2.452(2.662)$ & $2.854(2.903)$ \\
\hline
\end{tabular}




\title{
Conclusion
}

$\mathrm{PPy} / \mathrm{CNT} / \mathrm{NH}_{2}$-ITO composites were prepared by electropolymerization on diazoniummodified flexible ITO electrodes coated with CNTs, in the presence of the EGTA chelator. Polypyrrole was also prepared by electropolymerization on $\mathrm{NH}_{2}$-ITO and on bare ITO, without any CNTs. CNTs were easily removed from bare ITO, but resisted solvent washing on $\mathrm{NH}_{2}$-ITO flexible electrodes. Electrodeposition of PPy was found to be confined to the CNTs sidewalls as evidenced by SEM and the growth of the CNT diameter with the number of voltammetric cycles used to generate polypyrrole. The electropolymerization of PPy on CNT surface exhibits more expanded molecular conformation and more ordered chain packing, due to the strong $\pi-\pi$ and $n-\pi$ conjugation interactions between PPy and CNTs and the efficient template effect of CNTs during the electropolymerization. The increase of the electrochemical conductivity has been observed in the PPy deposited on CNT/ $\mathrm{NH}_{2}-\mathrm{ITO}$.

The PPy/CNT/ $\mathrm{NH}_{2}$-ITO composite electrodes were used for the electroanalysis of $\mathrm{Pb}^{2+}$ in aqueous media. The LOD was found to be $2.9 \times 10^{-9}$ mol. $\mathrm{L}^{-1}$ at $\mathrm{S} / \mathrm{N}=3$. Interestingly, EGTA was found to drastically improve the selectivity of the sensor towards $\mathrm{Pb}^{2+}$, as the response of the EGTA-containing sensor did not change even in the presence of relatively large concentration of competitive $\mathrm{Cu}^{2+}$ metal ions. Such improved selectivity imparted by EGTA is due to the higher EGTA- $\mathrm{Pb}^{2+}$ interaction energy $(-374.6 \mathrm{~kJ} / \mathrm{mol})$ compared to that of EGTA-Cu ${ }^{2+}(-116.4 \mathrm{~kJ} / \mathrm{mol})$ as judged from DFT calculations that consider solvation effects.

This work demonstrates conclusively the importance of diazonium salts to improve CNTs adhesion to ITO electrode surfaces serving as template for the in situ polypyrrole electrodeposition. The embedded CNTs impart remarkable properties to the polypyrrole sensing layers the selectivity of which is drastically improved using the EGTA chelator.

\section{Acknowledgements}

ML gratefully thanks the Cooperation and Cultural Action Service of the French Embassy in Senegal for a PhD grant. $\mathrm{AB}$ and $\mathrm{MMC}$ wish to thank NATO for financial support through the CATALTEX project No SfP 984842. All authors acknowledge Wallonie-Bruxelles International (Belgium) for the provision of a grant to ML within the framework of "Programme de Bourses d'Excellence". All authors thank M. Guerrouache for his assistance with Raman measurements.

\author{
Author Contributions: \\ Conceptualization of the research work by M.L., M.M.C.and D.G.-S. \\ Methodology by M.L., A.B. MS, and M.M.C.; \\ Validation by M.M.C., R.P., M.S., D.G.-S., J.-J.A., ZM, JD; \\ Formal Analysis by M.L., R.P., M.S., M.M.C., Z.M.; \\ Writing of Original Draft was done by M.L., M.S. and M.M.C.; \\ Writing: Review and Editing, M.L., M.M.C., J.-J.A., Z.M., J.D.; \\ Supervision, M.M.C., D.G.-S., Z.M.; \\ Funding Acquisition, J.-J.A., D.G.-S., Z.M.
}




\section{REFERENCES}

[1] Iijima, S.; Ichihashi, T.; Single-shell carbon nanotubes of 1-nm diameter. Nature. 1993, 364, 603-737.

[2] Al-Harbi, E. A. ; Abdelrahman, M. H. ; El-Kosasy, A. M. ; Ecofriendly Long Life Nanocomposite Sensors for Determination of Carbachol in Presence of Choline: Application in Ophthalmic Solutions and Biological Fluids. Sensors 2019, 19, 2357.

[3] George J.;Abdelghani, A.;Bahoumina, P.;Tantot, O.; Baillargeat, D.; Frigui, K.; Bila, S.; Hallil, H.; Dejous, C.; CNT-Based Inkjet-Printed RF Gas Sensor: Modification of Substrate Properties during the Fabrication Process. Sensors 2019, 19, 1768.

[4] Liu, Z.; Yang, T.; Dong, Y.; Wang, X.; A Room Temperature VOCs Gas Sensor Based on a Layer by Layer Multi-Walled Carbon Nanotubes/Poly-ethylene Glycol

Composite. Sensors 2018, 18, 3113.

[5]. Wang, J.; Du, S.; Onodera, T.; Yatabe, R.; Tanaka, M.; Okochi, M.; Toko, K. An SPR Sensor Chip Based on Peptide-Modified Single-Walled Carbon Nanotubes with Enhanced Sensitivity and Selectivity in the Detection of 2,4,6-Trinitrotoluene Explosives.

Sensors 2018, 18, 4461.

[6] Sun, X.; Zhang, H.; Zhou, L.; Huang, X.; Yu, C. Polypyrrole-Coated Zinc Ferrite Hollow Spheres with Improved Cycling Stability for Lithium-Ion Batteries. Small. 2016, 12, 37323737.

[ 7 ] Chen, S.; Zhitomirsky, I. Strategies to Optimize the Capacitive Behavior of PolypyrroleElectrodes.Mater. Manuf. Processes. 2016, 31, 2017-2022.

[8] Chen, S.; Zhitomirsky, I. Influence of Additives on Performance of Polypyrrole-Carbon Nanotube Supercapacitors.Mater. Manuf. Processes.2016, 31, 1246- 1252.

[9] Bharti, M.; Singh, A.; Samanta, S.; Aswal, D.K.; Conductive polymers: Creating their niche in thermoelectric domain, Prog. Mater. Sci.2018, 93, 270-310.

[10]Kotresh, S.; Ravikiran, Y.; Vijaya Kumari, S.; Chandrasekhar, T.; Ramana, C.V.; Thomas, S. Solution-based Spin Cast Processed Polypyrrole/Niobium Pentoxide Nanocomposite as Room Temperature Liquefied Petroleum Gas Sensor. Mater. Manuf. Processes. 2016, 31, 1976-1982.

[11] Muliwa, A.M.; Leswifi, T.Y.; Onyango, M.S.; Maity, A. Magnetic Adsorption Separation (MAS) Process: An Alternative Method of Extracting Cr (VI) from Aqueous Solution using Polypyrrole Coated $\mathrm{Fe}_{3} \mathrm{O}_{4}$ Nanocomposites. Sep. Purif. Technol. 2016, 158, 250-258.

[12] Bhaumik, M.; Agarwal, S.; Gupta, V.K.; Maity, A. Enhanced Removal of Cr (VI) from Aqueous Solutions using Polypyrrole Wrapped Oxidized MWCNTs Nanocomposites Adsorbent. J. Colloid Interface Sci. 2016, 470, 257-267.

[ 13 ]Sadki, S.; Schottland, P.; Brodie N.; Sabouraud, G. The mechanisms of pyrrole electropolymerization, Chem. Soc. Rev. 2000, 29, 283-293

[ 14 ]Wu, T.M.; Lin, S.-H.; Characterization and electrical properties of polypyrrole/multiwalled carbon nanotube composites synthesized by in situ chemical oxidative polymerization. J. Polym. Sci Part B. 2006, 44,1413-1418

[15] Park, S.J.; Kwon, O.S., Jang, J. A high-performance hydrogen gas sensor using ultrathin 
polypyrrole-coated CNT nanohybrids. Chem. Commun., 2013, 49, 4673-4675.

[16] Lu, Y.; Li, T.; Zhao, X.; Li, M.; Cao, Y.; Yang, H.; Duan, Y.Y. Electrodeposited polypyrrole/carbon nanotubes composite films electrodes for neural interfaces.

Biomaterials.2010, 31, 5169-5181.

[17] Hamouma, O.; Oukil, D.; Omastovà, M.; Chehimi, M.M. Flexible paper@carbon nanotube@polypyrrole composites: The combined pivotal roles of diazonium chemistry and sonochemical polymerization. Colloids Surf. A.2018, 538, 350-360

[18] Karim, M.R.; Lee C.J.; Chowdhury, A.M.S.; Nahar, N.; Lee, M. S. Radiolytic synthesis of conducting polypyrrole/carbon nanotube composites. Mater. Lett. 2007, 61, 1688-1692.

[19] Rahman, G.M.M.; Guldi, D.M.; Cagnoli, R.; Mucci, A.; Schenetti, L.; Vaccari, L.; Prato, M. Combining single wall carbon nanotubes and photoactive polymers for photoconversion. J. Am. Chem. Soc. 2005, 127, 10051- 10057.

[20] Cochet, M.; Maser, W.K.; Benito, A.M.; Callejas, M. A.M.; Martinez, T.; Benoit, J.M.; Schreiber, J.; Chauvet, O. Synthesis of a new polyaniline/nanotube composite:"in-situ" polymerisation and charge transfer through site-selective interaction. Chem. Commun. 2001, 0, 1450-1451.

[21] Bayrakçeken, H.; Naktiyok, J.; Özer, A.K.; Yurtcan, A.B. Investigation of the Thermal Behavior of Polypyrrole/Carbon Nanotube Composites and Utilization as Capacitive Material or Support for Catalysts. Chem. Eng. Commun. 2017, 204, 916-925.

[22] Cai, H.; Xu,Y.; He, P.G.; Fang, Y.Z. Indicator Free DNA Hybridization Detection by Impedance Measurement Based on the DNA - Doped Conducting Polymer Film Formed on the Carbon Nanotube Modified Electrode. Electroanalysis 2003, 15, 1864-1870.

[23] Gupta, S.; Murthy, C.N.; Ratna, P.C. Recent advances in carbon nanotube based electrochemical biosensors. Int. J. Biol. Macromol.2018, 108, 687-703.

[24] Cheraghi, S.; Taher, M.A.; Karimi-Maleh, H.; Faghih-Mirzaeide, E. A nanostructure label-free DNA biosensor for ciprofloxacin analysis as a chemotherapeutic agent: an experimental and theoretical investigation. New. J. Chem. 2017, 41, 4985-4989.

[25] Arulraj, A.D.; Sundaram, E.; Vasantha, V.S.;Neppolian, B. Polypyrrole with a functionalized multi-walled carbon nanotube hybrid nanocomposite: a new and efficient nitrite sensor. New J. Chem., 2018, 42, 3748-3757.

[26] Eom, G.; Oh, C.; Moon, J.; Kim, H.; Kim, M.K.; Kim, K.; Seo, Ji-W.; Kang,T.; Lee, H.J. Highly sensitive and selective detection of dopamine using overoxidized polypyrrole/sodium dodecyl sulfate-modified carbon nanotube electrodes. J.Electroanal. Chem.2019, 848, 113295

[27] Oularbi, L.; Turmine, M.; Rhazia, M.E. Preparation of novel nanocomposite consisting of bismuth particles, polypyrrole and multi-walled carbon nanotubes for simultaneous voltammetric determination of cadmium(II) and lead(II). Synth.Met.2019, 253,1-8.

[28] Lo, M.; Diaw, A.K.D.; Gningue-Sall, D.; Aaron, J-J.; Oturan, M.A.; Chehimi, M.M. The role of diazonium interface chemistry in the design of high performance polypyrrole-coated flexible ITO sensing electrodes. Electrochem. Commun. 2017, 77, 14-18.

[29] Lo, M.; Pires, R.; Diaw, K.; Gningue-Sall, D.; Oturan, M. A.; Aaron, J. J.; Chehimi, M. M. (2018). Diazonium salts: versatile molecular glues for sticking conductive polymers to flexible electrodes. Surfaces. 2018, 1, 43-58. 
[30] C. Perruchot, M. M. Chehimi, M. Delamar, E. Cabet-Deliry, B. Miksa, S. Slomkowski, M. A. Khan and S. P. Armes, Colloid Polym. Sci., 2000, 278, 1139.

[31] Lo, M.; Diaw, A.K.D.; Gningue-Sall, D.; Aaron, J.-J.; Oturan, M.A.; Chehimi, M.M. Tracking metal ions with polypyrrole thin films adhesively bonded to diazonium-modified flexible ITO electrodes. Environ. Sci. Pollut. Res. 2018, 25, 20012-20022.

[32] Hong, J., Pintauro, P. N. Selective removal of heavy metals from contaminated kaolin by chelators. Water, Air, Soil Pollution, 1996, 87, 73-91.

[33] Heitzmann, M.; Bucher, C.; Moutet, J.-C.; Pereira, E.; Bernabé, L. R.; Royal, G.; SaintAman, E. Complexation of poly(pyrrole-EDTA like) film modified electrodes: Application to metal cations electroanalysis. Electrochim. Acta 2007, 52, 3082-3087.

[34] Deshmukh, M. A; Bodkhe, G. A.; Shirsat, S.; Ramanavicius, A.; Shirsat, M. D. Nanocomposite platform based on EDTA modified Ppy/SWNTs for the sensing of $\mathrm{Pb}(\mathrm{II})$ ions by electrochemical method. Front. Chem. 2018, 6, Art. No 451.

doi: 10.3389/fchem.2018.00451

[35] Bhakta, A.K.; Detriche, S.; Martis, P.; Mascarenhas, R.J.; Delhalle, J.; Mekhalif, Z. Decoration of tricarboxylic and monocarboxylic aryl diazonium functionalized multi-wall carbon nanotubes with iron nanoparticles. J. Mater. Sci.2017, 52, 9648-9660.

[36] Fu, X.-C.; Wu, J.; Nie, L.; Xie, C.-G.,Liu, J.-H. ; Huang, X.-J. Electropolymerized surface ion imprinting films on a gold nanoparticles/single-wall carbon nanotube nanohybrids modified glassy carbon electrode for electrochemical detection of trace mercury(II) in water. Anal.Chim. Acta.2012, 720, 29-37.

[37]Tasis, D.; Tagmatarchis, N. ; Bianco, A. ; Prato, M. Chemistry of carbon nanotubes. Chem. Rev. 2006, 106, 1105-1136.

[38] Mohamed, A. A.; Salmi, S. ; Dahoumane, S. A. ; Mekki, A.; Carbonnier, B. ; Chehimi, M. M. Functionalization of nanomaterials with aryldiazonium salts. Adv. Colloid Interface Sci. 2015, 225, 16-36.

[39] Yu, S.S.C.; Tan, E.S.Q.; Jane, R.T.; Downard, A.J. An electrochemical and XPS study of reduction of nitrophenyl films covalently grafted to planar carbon surfaces. Langmuir 2007, 23, 11074-11082.

[40] Pilan, L.; Raicopol, M.; Pruna, A.; Branzoi, V. Polyaniline/carbon nanotube composite films electrosynthesis through diazonium salts electroreduction and electrochemical polymerization. Surf. Interface Anal. 2012, 44, 1198-1202.

[41] Liu, Y-C.; McCreery, R.L.; Reactions of Organic Monolayers on Carbon Surfaces Observed with Unenhanced Raman Spectroscopy, J. Am. Chem. Soc.1995,117, 11254-11259

[42] Song, H.; Cai, K.; Wang, J.; Shen, S.; Influence of polymerization method on the thermoelectric properties of multi-walled carbon nanotubes/polypyrrole composites. Synt. Met. 2016, 211, 58-65.

[ 43 ] Afzal, A.; Abuilaiwi, F.A.; Habib, A.; Awais, M.; Waje, S.B.; Atieh, M.A. Polypyrrole/carbon nanotube supercapacitors: Technological advances and challenges, $J$. Power Sources. 2017, 352, 174-186.

[44] Bensghaïer, A.; Truong, S.L.; Seydou, M.; Lamouri, A.; Leroy, E.; Matej, M.; Forro, K.; Beji, M.; Pinson, J.; Omastova, M.; Chehimi, M.M. Efficient Covalent Modification of Multiwalled Carbon Nanotubes with Diazotized Dyes in Water at Room Temperature, 


\section{Langmuir. 2017, 33, 6677-6690.}

[45] Hicks, M.; Wong, Z.Y.; Scurr, D.J.; Silman, N.; Jackson, S.K.; Mendes, P.M.; Aylott, J.W.; Yi, Z.; Rawson F.J. Tailoring the Electrochemical Properties of Carbon Nanotube Modified Indium Tin Oxide via in Situ Grafting of Aryl Diazonium. Langmuir, 2017, 33, 4924-4933.

[46] Boukerma, K.; Omastová, M.; Fedorko, P.; Chehimi, M. M. Surface properties and conductivity of bis (2-ethylhexyl) sulfosuccinate-containing polypyrrole. Appl. Surf. Sci. 2005, 249, 303-314.

[47] Jlassi, K.; Singh, A.; Aswal, D. K.; Losno, R.; Benna-Zayani, M.; Chehimi, M. M. Novel, ternary clay/polypyrrole/silver hybrid materials through in situ photopolymerization. Colloids Surf. A 2013, 439, 193-199.

[ 48 ] Chamjangali, M.A.; Kouhestani, H.; Masdarolomoor, F.; DaneshinejadH.;A voltammetric sensor based on the glassy carbon electrode modified with multi-walled carbon nanotube/poly(pyrocatecholviolet)/bismuth film for determination of cadmium and lead as environmental pollutants. Sens. Actuators B. 2015, 216, 384-393.

[49]Lee, C.; Yang, W.; Parr, R. G. Development of the Colle-Salvetti correlation-energy formula into a functional of the electron density. Phys. Rev. B,1988, 37, 785-789.

[50] Frisch, M. J., Trucks, G. W, Schlegel, H. B., Scuseria, G. E., Robb , M. A., Cheeseman, J. R., Scalmani, G., Barone, V., Mennucci, B., Petersson, G. A., Nakatsuji, H., Caricato, M., Li, X., Hratchian, H. P., Izmaylov, A. F., Bloino, J., Zheng, G., Sonnenberg, J. L., Hada, M., Ehara, M ., Toyota, K., Fukuda, R., Hasegawa, J., Ishida, M., Nakajima, T., Honda, Y., Kitao, O., Nakai, H., Vreven, T., Montgomery, J. A. Jr, Peralta, J. E., Ogliaro, F., Bearpark, M., Heyd, J. J., Brothers, E., Kudin, K. N., Staroverov, V. N., Kobayashi, R., Normand, J., Raghavachari, K., Rendell, A., Burant, J. C., Iyengar, S. S., Tomasi, J., Cossi, M., Rega, N., Millam, J. M., Klene, M., Knox, J. E., Cross, J. B., Bakken, V., Adamo, C., Jaramillo, J., Gomperts, R., Stratmann, R. E., Yazyev, O., Austin, A. J., Cammi, R., Pomelli, C., Ochterski, J. W., Martin, R. L., Morokuma, K., Zakrzewski, V. G., Voth, G. A., Salvador, P., Dannenberg, J. J., Dapprich, S., Daniels, A. D., Farkas, Ö., Foresman, J. B., Ortiz, J. V., Cioslowski, J., Fox, D.J. 2009. Gaussian, Inc., Wallingford CT.

[51] Dasent, pps. 44-47; Moore,C.E. "National Standard Reference Data Series," National Bureau of Standards, No. 34, Washington, DC, 1970; Martin, W.C.;Hagan, L.;Reader, J.;Sugar, J. J. Phys. Chem. Ref. Data, 1974, 3, 771-779.

[52] Barone, V.; Cossi, M.; Tomasi, J. A New definition of cavities for the computation of solvation free energies by the polarizable continuum model. J. Chem. Phys., 1997,107, 32103221. 